\title{
Vascular Disease in Patients with Multiple Sclerosis: A Review
}

Caprio MG', Russo $C^{2}$, Giugliano ${ }^{2}$, Ragucci $\mathbf{M}^{2}$ and Mancini $\mathbf{M}^{\text {1* }}$

${ }^{1}$ Institute of Biostructures and Bioimaging, National Research Council, Italy

${ }^{2}$ Department of Advanced Biomedical Sciences, University "Federico II", Italy

\begin{abstract}
Background: despite major advances in immunology and molecular biology, Multiple Sclerosis is poorly understood with regards to etiology and its immune trigger and causal pathways are substantially unknown. In recent years, vascular abnormalities associated with Multiple Sclerosis have been investigated, opening the doors to the hypothesis that in the pathogenesis of multiple sclerosis a vascular component could be important. Different forms of vascular abnormalities have been associated with MS: increased risk for ischemic disease, cerebral hypoperfusion, abnormalities of endothelial cells and impaired venous drainage. The aim of this review was to describe literature evidence concerning the correlation between Multiple Sclerosis and vascular dysfunction, cardiovascular risk factors and major cardiovascular events.
\end{abstract}

Methods: A literature review was performed using the following databases and web search engines: PubMed US National Library of Medicine; Google Scholar; and Ovid MEDLINE. The search included the following combination of terms: "multiple sclerosis" and endothelial dysfunction or vascular dysregulation or vascular hypothesis or risk factors or cardiovascular disease or venous thromboembolism or epidemiology. The selected articles were divided into six macro-groups according to the topic of the paper: cardiovascular risk; cardiovascular diseases; microcirculation factors; venous alterations; infectious pathogens; and vascular adverse effects of therapy.

Results: patients with Multiple Sclerosis seem to have more cardiovascular risk factors and an increased risk for ischemic stroke. Several studies have demonstrated cerebral perfusion abnormalities. The relationship between the disturbances in cerebral venous outflow and neurological disorders remains an open issue that requires further studies.

Conclusion: Recent evidence suggests that vascular components may be initiating triggers for neuronal pathology and subsequent neurological manifestations of the disease. The high degree of comorbidity between vascular disease and Multiple Sclerosis suggests that vascular pathology may be an important factor causing neuronal dysfunction or degeneration in multiple sclerosis.

Keywords: Multiple sclerosis; Cardiovascular risk factors; Ischemic stroke; Vascular abnormalities; Cerebral venous outflow; Review

\section{Introduction}

Multiple sclerosis (MS) is a neurodegenerative disorder that affects the central nervous system (CNS), sparing the peripheral nervous system and revealing its first signs in early adulthood, with a variable clinical course ranging from a benign condition to a rapidly evolving disabling disease [1]. MS is the most common disease of the CNS and the most common cause of neurological disability in young adults, affecting approximately 2.5 million worldwide, with variable progression and prognosis $[1,2]$. The incidence and prevalence rates of MS vary considerably between regions and populations, showing a typical latitudinal gradient probably due to genetic and behavioral variations [3]. Europe is considered a high frequency area for MS (prevalence $\geq 30 / 100,000$ ); other high prevalence regions include the northern USA, Israel, Canada, Southern Australia, New Zealand and Eastern Russia [4]. Chronic inflammation, perivenular cuffing, demyelization, gliosis and neuronal loss are hallmarks of the pathology, producing plaque formation and tissue destruction not only in the white matter but also in the cerebral cortex. Despite major advances in immunology and molecular biology, MS is poorly understood with regards to etiology and its immune trigger and causal pathways are substantially unknown. Moreover, how etiopathological mechanisms influence the course of this disease remains unclear [5-8]. Studies with magnetic resonance imaging (MRI) have demonstrated that white matter lesions correlate weakly with neurological disability and longitudinal studies involving MS patients have shown accelerated grey matter atrophy as consequence of grey matter lesions. Grey matter (GM) atrophy correlates with physical and cognitive disability more strongly than white matter atrophy. Many theories have been developed, and many potential causes have been identified: genetic predisposition, environmental factors, infections, vascular risk factors, and traumatic brain injury. Moreover, it is not known why some patients develop clinically asymptomatic MS with a benign course, while other patients experience relapses with permanent neurological deficits or progressive and massive disability. Vascular pathology in MS patients was investigated by authors and noted by Charcot in his identification of MS; however, vascular abnormalities associated with MS have been investigated only in recent years, opening the doors to the hypothesis that in the pathogenesis of multiple sclerosis a vascular component could be important [1,9-11]. Assuming that endothelial dysfunction and chronic inflammation play an integral role in CNS lesions pathogenesis, many authors have decided to elucidate the primary and secondary effects of these mechanisms regarding the

*Corresponding author: Mancini M, Institute of Biostructures and Bioimaging, National Research Council, via Tommaso De Amicis 95 -80145 Naples, Italy, Tel: +39 081 2203411; Fax: +39 081 2203498; E-mail: direttore@ibb.cnr.it

Received February 23, 2016; Accepted March 04, 2016; Published March 11, 2016

Citation: Caprio MG, Russo C, Giugliano A, Ragucci M, Mancini M (2016) Vascular Disease in Patients with Multiple Sclerosis: A Review. J Vasc Med Surg 4: 259. doi:10.4172/2329-6925.1000259

Copyright: (c) 2016 Caprio MG, et al. This is an open-access article distributed under the terms of the Creative Commons Attribution License, which permits unrestricted use, distribution, and reproduction in any medium, provided the original author and source are credited. 
vasculature in MS patients compared to that in the healthy population. Fundamentally, different forms of vascular abnormalities have been associated with MS: increased risk for ischemic disease, arterial cerebral hypoperfusion, abnormalities of endothelial cells and impaired venous drainage. The aim of this review is to describe literature evidence concerning the relationship between MS and vascular dysfunction, cardiovascular risk factors and major cardiovascular events.

\section{Materials and Methods}

A literature review was performed using the following databases and web search engines: PubMed - US National Library of Medicine; Google Scholar; and Ovid MEDLINE. A text search was also performed: "The epidemiology of Neurological Disorders", Compston et al. BMJ Books, London, 1998; "Principles of Neurology", Chapter 36, Multiple Sclerosis and Allied Demyelinating Diseases, Adams et al., McGraw-Hill, 1997; "Neurological disorders: public health challenges", World Health Organization 2006, WHO Library; and "McAlpine's Multiple Sclerosis" - Fourth Edition, Alastair Compston, Churchill Livingstone Elsevier, 2006. In addition, a manual search of reference lists from original articles was performed. The search included the following combination of terms: "multiple sclerosis" and "endothelial dysfunction" or "vascular dysregulation" or "vascular hypothesis" or "risk factors" or "cardiovascular disease" or "venous thromboembolism" or "epidemiology". We considered articles and publications from 1830 to 2015; the research was limited to texts and articles published in English or with available translation into English. We referenced primary sources, using secondary papers exclusively when the primary sources were not available. Our initial search yielded 3842 articles whose abstracts were reviewed; the selection of the articles was performed based on the agreement between the authors MGC, CR, AG and MM. Of the 3842, we excluded different studies from the same research group concerning similar findings or overlapping populations with redundant collected data. We also excluded case-reports or studies with a small sample population size (fewer than 20 patients). At the end of the selection procedure, 3643 articles had been excluded. The selected articles were divided into six macro-groups according to the topic of the paper: cardiovascular risk; cardiovascular diseases; microcirculation factors in MS; venous alterations; MS and infectious pathogens; and vascular adverse effects of MS therapy (Figure 1) and (Table 1 as supplementary material). All the articles mentioned in this review are included in the final reference list.

\section{Results}

\section{Cardiovascular risk}

Many authors have discussed the association between MS and classical/non-classical cardiovascular (CV) risk factors, analyzing this issue from different points of view and trying to elucidate the impact of these factors on the underlying disease [10-13]. The most salient evidence from the literature is the higher prevalence of traditional risk factors in patients with MS and the change in clinical outcomes produced by the presence of one or more CV risk factors. The prevalence increases with age and is higher in man. It was also shown an increased risk of ischemic heart disease, ischemic stroke and peripheral vascular disease [14]

The simultaneous presence of individual or multiple $\mathrm{CV}$ risk factors is related to the increased accumulation of white matter lesions, decreased grey matter and cortical volume and consequential accelerated brain atrophy [15]. In the subsections below, the various classical and non-classical cardiovascular risk factors and their relationship with MS will be considered separately.

Obesity: Observational studies analyzing the prevalence of overweight and obesity in MS in comparison with the general population are inconclusive. Among MS patients, the combined prevalence of overweight (Body mass index (BMI) $\geq 25 \mathrm{~kg} / \mathrm{m}^{2}$ ) and obesity $\left(\mathrm{BMI} \geq 30 \mathrm{~kg} / \mathrm{m}^{2}\right)$ is approximately between $50 \%$ and $65 \%$ in large sample sizes. These estimates are similar to those of the nondiseased adult population. Some studies in childhood and adolescence showed an association between BMI and the risk of developing multiple sclerosis [16]. Instead this association was not found in adults. These data suggest that the prevention of obesity in adolescence may reduce the risk of MS $[17,18]$.

In other studies a lower prevalence of obesity in MS patients compared to controls has been reported $[19,20]$. In contrast, the prevalence of metabolic syndrome seems similar to that of the general population and waist circumference seems to increase among disabled MS patients. The paradox of the discrepancy between the prevalence of high BMI and metabolic syndrome can be explained by the lower ratio of muscle to fat in disabled patients. Therefore, the use of waist circumference, instead of BMI, as a cardiovascular risk factor in these patients could be recommended.

The association between BMI and disability was examined in four studies. In two of these studies, the BMI, was calculated using weight and height self-reported. Thus represents a potential limitation because overweight patients frequently to under-report their weight [17].

Only one study clearly demonstrated a correlation between BMI and disability [21]. This study showed a correlation of BMI and almost all the determinants of serum lipids and Apo lipoproteins with disability as assessed by Expanded Disability Status Scale (EDSS). After adjusting the analysis for BMI and physical activity the magnitude of BMI and disability persisted.

Levels of vitamin D: The importance of vitamin D as a risk factor of MS has been demonstrated in several studies [22-24]. One study showed that women who took vitamin D supplements had a $40 \%$ lower risk of developing MS [25]. Recent studies also describe a relationship between low levels of vitamin $\mathrm{D}$ and relapses and disease progression [26]. Moreover, low vitamin D levels are correlated with both MS and cardiovascular disease $[27,28]$. The studies are not yet conclusive; however, a growing body of evidence supports a protective role for vitamin D in MS development.

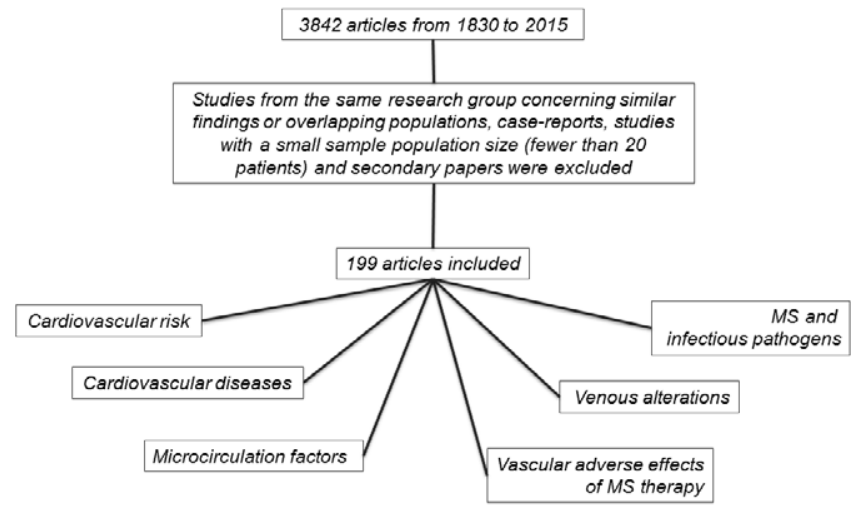

Figure 1: This flowchart describes the systematic literature review, which were selected papers included in the study. 
Vitamin $\mathrm{D}$ is a potent immunomodulatory [29] and some studies have shown that administration of the active hormone 1,25-dihydroxyvitamin $\mathrm{D}$ prevents the onset and slows the progression of the disease in mice $[30,31]$.

It is unknown the exact mechanism of this protection; it could be an indirect effect, possibly mediated by regulatory $\mathrm{T}$ cells [32] that are suppressed in individuals with MS [33].

Serum levels of vitamin $\mathrm{D}$ are regulated by exposure to UV radiation from sunlight. The exposure to UV light whole body suppresses EAE in mice [34], enhances the function of regulatory $\mathrm{T}$ cells and increases the production of immunosuppressive cytokines interleukin 4 and interleukin 10 [35].

The risk of developing MS among migrants is higher when migrations occurs in childhood and tend to decrease with increasing age [36]. Therefore the level of vitamin D in childhood may confer a protection for the development of MS.

In literature, there are few data on vitamin D levels earlier in life and risk of MS. At ages 16 and 19 years was demonstrated on association between the risk of multiple sclerosis and the levels of 25-hydroxyvitamin D.

In conclusion, it is not clear if you can reduce the incidence of MS in high-risk populations, increasing circulating levels of 25-hydroxyvitamin $\mathrm{D}$. We need more evidence to support the observational studies alone.

Diabetes: A cohort study [37] including $98 \%$ of the pediatric diabetic population in Austria and Germany below the age of 21 years analyzed the RR of MS co-occurrence and demonstrated that the RR for MS in type 1 diabetes was three to almost five times higher than that in the healthy population.

This study shows that children and adolescents with diabetes have a greater risk of developing MS. The risk for the development of MS was higher in diabetic patients born during spring and summer; therefore environmental factors can affect the risk for the onset of both diseases.

In studies on the Sardinian population, there was a prevalence of type 1 diabetes by two to five times greater in adult patients with MS than the general population. $[38,39]$.

Studies on the prevalence of type-2 diabetes (T2D) in patients with MS compared to subjects without MS have contradictory results. The studies on type - 2 diabetes in MS patients are inconclusive. Hospitalized MS patients showed a lower frequency of T2D compared to healthy controls $[19,40]$.

Outpatients with MS showed a higher prevalence of diabetes than that in the general population $[40,41]$ which was not observed in other studies [42-44].

Marrie and colleagues using the NARCOMS registry, comparing MS patients with and without T2D showed in the first group a $29 \%$ increased risk of early gait disability [43,45]. Furthermore, the development of T2D during the course of the disease has led to a $35 \%$ increased risk of mild visual impairment, $41 \%$ of moderate visual disability and 54\% of visual impairment [46].

Hypertension: The data on the prevalence of hypertension in MS are contrasting. Some studies have reported no differences or a lower prevalence of hypertension in MS cases compared to controls $[13,19,40,44,45,47]$. Kang and colleagues observed a higher frequency of hypertension among MS cases $(n=898)$ compared to controls [42].
In 2012, La Vela and colleagues compared 1,142 male MS veterans with healthy veterans and with the general population: hypertension was more frequent in the first group than in the second group and the general population (respectively $47.6 \%, 41.2 \%$, and $20.9 \%$ ) [48].

Studies that evaluated the relationship between hypertension and disability reported that the presence of arterial hypertension could influence the development of disability in MS patients. The presence of hypertension at any time in the disease was associated with a $29 \%$ increased risk of early gait disability [45] and a 32\% increased risk of visual disability [46].

Dyslipidemia: Case-control studies reported higher total and LDL cholesterol in MS patients compared with control subjects [42,49-51]. A significant worsening in expanded disability status scale was concomitant with higher baseline low-density lipoprotein and total cholesterol levels [52]; a prospective study showed a direct association between higher ratio of total cholesterol to high-density lipoprotein and deterioration in EDSS [20]. Higher serum high-density lipoprotein levels were associated with lower contrast-enhancing T1weigthed lesion volume, therefore with a protective effect in the acute inflammatory phase. Contrast enhancement in T1-weighted images corresponds to focal areas of impairment of the blood-brain barrier (BBB), associated with acute inflammatory infiltration [53]. Therefore, these enhancing lesions are a marker of active disease [54]. The assumption is that apolipoprotein A-1 and paraoxonase anti-oxidant enzyme associated with high-density lipoprotein may participate to its anti-oxidant and anti-inflammatory activities. [49,50,55-58].

A negative effect of hypercholesterolemia on the development of disability was demonstrated by Weinstock-Guttman and colleagues in 2011 that reported the relationship between adverse lipid profile and an increased number of new T2 lesions [59].

Moreover Swank and colleagues found that a diet low in saturated fats and supplemented with vegetable oils provides benefits on the progression of MS and on disability [60,61].

Cigarette smoking: Compared to non-smokers, the risk of MS in smokers is about $50 \%$ greater and is correlated with the duration and with the amount of smoking [62-66].

In a study of a large number of nurses [61], the risk of MS is about twice as high among women who smoked $\geq 25$ pack-years (equivalent to smoking a pack of cigarettes a day for more than 25 years) than nonsmokers. The negative effects of smoking on the risk of MS appear even higher among men than women, with some studies reporting a nearly three-fold increased risk in male never smokers compared to male never smokers [66-68]. It was observed that only the tobacco smoke, but not the snuff, is associated with an increased risk of MS; from this it follows that the combustion plays an important role for toxicity [66].

Mechanisms underlying the effects of smoking on the risk of MS are still unknown. Mechanisms hypothesized are: effects on demyelination $[69,70]$, effects on the breaking of the blood-brain barrier [71], immunomodulatory effects $[72,73]$ and an increase in nitric oxide metabolites and nitric oxide [74].

A study conducted on a population of 1465 MS patients showed a negative influence of smoking on the progression of the disease [75]. At baseline smokers have a worse disease than non-smokers and exsmokers in terms of EDSS and multiple sclerosis severity score (MSSS). EDSS and MSSS were directly correlated with the number of pack-years smoked at baseline. A longitudinal analysis reported no relationship between smoking and progression EDSS at 2 and 5 years. However, 
there was an earlier conversion from relapsing remitting multiple sclerosis (RRMS) to secondary progressive multiple sclerosis (SPMS) in smokers than in non-smokers and ex-smokers. MRI showed a greater increase in the volume of $\mathrm{T} 2$ lesions and a greater reduction of brain parenchymal fraction in smokers than non-smokers and ex-smokers $[62,76]$.

Hyperhomocysteinemia: Some authors have described hyperhomocysteinemia (Hcy), a risk factor for thromboembolic disease [77], in the serum of MS patients and linked this finding to an increased risk of intercurrent vascular diseases [78-80]. Neurons may be particularly susceptible to Hcy-induced excitotoxicity, with the hypomethylation of myelin basic proteins and consequent lack of myelin structure stability [81]. Significantly higher serum levels of homocysteine were found in MS patients compared to healthy controls, even in the absence of the methylenetetrahydrofolate reductase (MTHFR) mutation [82-85]. Hyperhomocysteinemia was also related to cognitive impairment in patients with MS [86], and high levels of Hcy with low levels of folate/vitamin B12 were associated with higher EDSS scores [87]. However, the clinical implications of literature findings about the relationship between hyperhomocysteinemia and MS are not completely clear, requiring further studies to elucidate the prognostic implications of this evidence [82].

\section{Cardiovascular diseases}

Several studies have reported an increased cardiovascular morbidity in MS patients and that the mortality related to stroke and cardiovascular disease was higher in MS patients compared to the general population $[88,89]$.

MS patients who reported more than one CV risk factor at the time of diagnosis had an increased chance of ambulatory disability and this risk increased with the number of reported CV risk factors $[9,45,90]$.

Although studies do not provide data on the pathogenesis of cardiovascular disease in MS patients, inflammation and autoimmunity are central to the pathogenesis of MS and endothelial dysfunction, which is a precursor of atherosclerosis and arterial vascular diseases. The activated endothelium has pro-coagulant properties and is a central component of the anti-phospholipid syndrome, associated with MS and venous thromboembolism [91]. Moreover, platelet activation in MS could increase thromboembolic events.

Stroke: Patients with chronic inflammation of the central nervous system, have a higher risk of developing cardiovascular disease, including ischemic stroke [92-95]. The cause may be endothelial dysfunction, induced by chronic inflammation, resulting in progress of atherosclerosis and cardiovascular disease $[96,97]$ such as stroke.

Few studies have associated MS with the development of ischemic stroke $[11,98]$. Allen et al. conducted a cross-sectional study on hospitalized patients. MS was associated with a higher prevalence of the concurrent primary diagnosis of ischemic stroke compared to other inpatients but not with hemorrhagic stroke [19]. In addition, other authors observed a higher risk of stroke and cerebrovascular diseases in MS patients compared to the control population $[42,98,99]$. A large Danish cohort study showed an increased relative risk that was very pronounced for young patients [11]. Similarly, in a recent Swedish cohort study MS was associated with significantly increased relative risks for cerebrovascular disease. However, in this study, after the first year of follow-up, the overall relative risk of occurrence of cerebrovascular disease and in particular cerebral infarction was not statistically significant. In a recent study in Taiwan, a database of 22 million people, recruited by the National Health Insurance (NHI) database, was used to evaluate the association between MS and ischemic stroke in 1174 patients with multiple sclerosis and 4496 controls, randomly selected and monitored in follow-up for 14 years. Patients with multiple sclerosis showed an increased risk of stroke compared to the control population in the first 5 years of follow-up. Among participants without comorbidities, multiple sclerosis group shows a risk of ischemic stroke higher than healthy controls. Also in a subset of the population aged $<40$ years, patients with multiple sclerosis had a significantly increased risk of stroke. Therefore, patients with multiple sclerosis, in particular young people, should be carefully monitored for stroke prevention (99).

Ischemic heart disease: In a study by Allen et al. admission with a principal diagnosis of myocardial infarction was less frequent in MS patients than in other hospitalized patients [19]. In addition, Fleming and Blake observed a lower frequency of acute myocardial infarction and heart failure in MS cases than in matched hospitalized controls [40]. A Swedish cohort study showed an overall non-statistically significant inverse association with ischemic heart disease [100]. In contrast, many studies showed an increased relative risk for ischemic heart disease in MS patients. A cross-sectional study by Lindegard et al. comparing MS patients with the general population showed a prevalence of myocardial infarction that was four to six times higher in MS patients [101].

Two studies demonstrated that patients with multiple sclerosis have an increased of risk of death from cardiovascular disease by 32$34 \%$ compared to the general population [88-102]. Other studies have also shown an increased risk of myocardial infarction and heart failure in the MS group compared to the control group [11,98]. Finally other studies reported a higher rate of coronary heart disease $[42,98]$ and ischemic heart disease [103] in MS patients compared to controls.

Venous thromboembolism: Many autoimmune diseases are associated with an increased risk of venous thromboembolism (VTE) [104,105]. An increased risk of VTE was observed in MS. An increased incidence of VTE in patients with MS was reported [106107], especially during the first year after diagnosis [108]. Peeters et al reported a risk of venous thromboembolism 2.5 times higher in MS patients compared with healthy subjects. According to the authors, this association can be explained by presence in MS patients of disability and glucocorticoids therapy [109]. Only one study relieved a lower risk of VTE in MS patients. The authors hypothesized that muscle spasm could favor the venous return with a non-effective emptying of veins of lower limb, reduction of venous stasis and consequently lower of risk of deep venous thrombosis [110].

\section{Microcirculation factors in MS}

Endothelial dysfunction: Together with the loss of myelin and the glial proliferation, perivascular infiltration and endothelial damage have been described as histological findings in the brain tissue of patients with MS [111]. This observation has led to the hypothesis that a possible vascular factor should be involved in the pathogenesis of multiple sclerosis [112]. In particular, vessels in the pathological area showed changes that are typical of chronic inflammation. Many factors have been associated with chronic inflammation and oxidative damage in multiple sclerosis lesions [113-117]. Endothelin-1 (ET1 ) is a vasoconstrictor peptide that is regulated by a large number of vasoactive agents [118] and, should play a role in endothelial damage and vascular pathological reaction. It has been suggested that ET-1 plasma level dysregulation may lead to excessive vasoconstriction 
or insufficient vasodilatation, resulting in vasospasm and reduced cerebral blood flow (CBF) [119]. In some studies, (ET-1) plasma levels measured in a blood sample taken from one of the main routes of venous efflux from the brain were significantly elevated in patients with MS compared to healthy controls; this increase could lead to chronic cerebral hypoperfusion, especially in the more susceptible white matter, with resulting myelin damage and progressive neuronal loss [118]. Moreover, during immunomodulatory treatment MS patients showed a significant reduction in ET-1 plasma levels [120]. Other elements frequently associated with MS lesions include endothelial micro-particles, endothelial cell adhesion molecules (selectins, integrins, ICAMs, VCAMs, JAMs, lymphoid chemokines and their receptors), pro-inflammatory cytokines and vascular growth factors. The overexpression of these molecules should participate in the vascular remodeling that is typical of multiple sclerosis, in a deleterious cascade. Over time these elements should lead to cerebral endothelial junctional disorganization, pathological iron deposition, immune cell extravasation and metabolic disorders leading to massive apoptosis, which culminate in the loss first of neural and then of glial cells [113$117,121,122]$ associated with a variable degree of brain atrophy, with permanent disability and cognitive impairment [123].

In addition, autoimmune mechanisms targeting the central nervous system myelin have long been proposed, but not proved. Th17 cells producing interleukin-17 and Th1 cells producing interferongamma are postulated to play major roles in initiating inflammation while regulatory $\mathrm{T}$ cell functions are dampened [124].

Alterations in peripheral blood mononuclear cell (PBMC) cytokine production have been found in patients with MS compared to healthy controls. Stimulated PBMC-produced TNF- $\alpha$ and IFN- $\gamma$ modulated MS relapse risk, such that increased TNF- $\alpha$ was protective, while increased IFN- $\gamma$ increased relapse risk. Zhou et al. reported the novel modulation of TNF- $\alpha$ and IFN- $\gamma$ associations with relapse by SNPs in major cytokines [125].

Adult human astrocytes stimulated with interferon- $\gamma$, a common inflammatory cytokine that is evidently present in neuropathological brains, exert potent neurotoxicity in vitro. This interferon- $\gamma$-induced astrocytic neurotoxicity is mediated by the activation of the Janus kinasesignal transducer and activator of transcription (STAT) 3 pathways in astrocytes and involves the intracellular phosphorylation of STAT3 at the tyrosine-705 residue. Therefore, the control of STAT3 activation in human astrocytes may be a promising new therapeutic strategy for a broad spectrum of neurodegenerative and neuroinflammatory disorders where activated astrocytes may contribute to the pathology [126].

Platelet abnormalities: In MS, as result of endothelial lesions, can occur a platelet activation, which markers are Platelet microparticles and CD62 $p$ expression. Sheremata et al showed, in MS patients, elevated levels of plasmatic endothelial micro particles positive for platelet endothelial cell adhesion molecule-1(CD31/PECAM). This may be expression of the interaction of activated T-cells with the endothelium. This interaction may play a role in the abnormalities involved in the pathophysiology of MS.

The findings of this study demonstrate that platelets are significantly activated in MS patients. However, their role in the pathogenesis of MS remains unknown. [127].

Perfusion abnormalities: Perfusion-weighted MRI was used to demonstrate abnormalities of regional cerebral hemodynamics in MS, by using both exogenous tracers (eg, gadolinium-based contrast agents) and endogenous arterial water (arterial spin labeling). It was found that, while enhancing lesions showed increased perfusion, chronic MS lesions showed reduced perfusion. In particular, disruption of the bloodbrain barrier was described before and during the development of focal MS lesions and it is represented by a local gadolinium-enhancing area on T1w MR imaging [128]. Diffuse enhancing areas were characterized by increased $\mathrm{CBF}$ and $\mathrm{CBV}$ [129]; while ring-enhancing areas $\mathrm{CBF}$ and $\mathrm{CBV}$ were increased in the ring tissue, $\mathrm{CBF}$ was reduced inside the ring. Because of the similarity with acute ischemia, this finding is evocative for a focal central ischemic zone and it suggests that focal ischemia should play a crucial role in the development of some type of focal MS lesions $[129,130]$. Law et al, using dynamic susceptibility contrast MR (DSC-MR) imaging, demonstrate a decreased cerebral blood flow and a prolonged mean transit time in periventricular regions of normal appearing white matter (NAWM) in MS patients compared with controls [131]. Other studies showed diffuse hypoperfusion in various regions (NAWM, cortex and deep GM) independently of the clinical MS variant of the patient $[132,133]$. These changes in brain tissue perfusion were correlated to clinical disability and neuropsychological impairment [134]. One study [135] reported a correlation between decreased perfusion and decreased mean diffusivity in the corpus callosum of patients with RRMS, a finding more consistent with what is seen in primary ischemia than in secondary hypoperfusion. The data of perfusion-weighted MR imaging were confirmed by a study in which the spatial distribution of the MS lesions were compared with images of a SPECT (Single-Proton Emission-Computed Tomography) atlas of healthy individuals. Lesions were localized in relatively lower normal perfusion areas than normal appearing white matter areas [136].

\section{Venous alterations}

Over a century ago, researchers were considering the role of abnormal venous in MS. Subsequently, more recently a small but important body of research, including Zamboni's work, contributed to extend early observations.

The first observations on vascular anomalies were documented by French anatomist Cruveilhier [137] in 1839, who studied the differences between areas of sclerosis and results of embolic events. In 1863, Rindfleisch [138] described an engorged blood vessel in the center of the plaques in autopsy specimens of MS brains and in the same period, Charcot [5] noted the constant presence of vascular obstruction in MS Further evidence of the vascular mechanical effect comes from the observations of Putnam that studied the effects of obstructed venous flow in the brain of dogs and recorded the development in these animals of various abnormalities similar to encephalitis or multiple sclerosis. Fog stated that MS lesions typically developed around small veins $[139,140]$. Further evidence of the vascular mechanical effect comes from Allen's observations, who noticed the wide vascular beds around veins and the central widening of the venous tree that testifies an intermittent increase in cerebral pressure [141]. During 1980's, studying MS plaque development, Adams confirmed the crucial contribution of vascular anomalies [121].

In 2006 [142], Dr. Zamboni presented a paper recorded some similarities between Chronic Venous Disease and MS, including presence of iron/fibrinogen deposition. From the first observation of MS up to modern MRI studies, a possible connection between MS and vascular system is evident.

In MS the visibility of small medullary vein is reduced [143], and the cerebral circulation time is increased [144]. All these results demonstrate that hemodynamic abnormalities and a vascular compromise are 
associated with MS. Zamboni and colleagues proposed that chronic cerebrospinal venous insufficiency (CCSVI) and secondarily venous hypertension can lead to increase iron deposition along venous pathway. The iron deposition within the brain parenchyma leads to the inflammation and tissue injury seen in MS [145]. Whether observed increase in iron in the central nervous system is etiologic to MS or the result of MS is a fundamental and yet unanswered question in the debate of CCSVI and MS. The morphological basis of the abnormalities in venous return are intraluminal defects as septa, membranes and anomalies of valves in the internal jugular vein (IJV) and azygos vein, compression muscle, hypoplasia or agenesis.

In 2009 [146], Dr. Zamboni using duplex ultrasonography identified CCSVI as a vascular condition characterized by anatomical and functional abnormalities of the intra- and extra-cranial veins with flow anomalies and presence of collateral venous channels and demonstrated a correlation between CCSVI and MS.

The outflow anomaly focused in particular on 5 anomalous parameters of cerebral venous drainage:

1. Reflux constantly present in IJV and/or Vertebral Veins (VVs) with the head at $0^{\circ}$ and $90^{\circ}$ assessed as flow reversal from physiologic direction for a duration of $>0.88 \mathrm{~s}$.

2. Bidirectional flow (or reflux) in the intracranial veins and sinuses.

3. High-resolution B-mode ultrasound evidence of proximal stenosis of the IJV (Cross sectional area $(\mathrm{CSA})<0.3 \mathrm{~cm}^{2}$ ).

4. Absence of detectable flow in the IJV and/or VVs despite numerous deep inspirations with the head positioned at $0^{\circ}$ and $90^{\circ}$.

5. Abnormal change of the IJV CSA with change in position (negative $\triangle$ CSA).

In the study of Zamboni the presence of at least two of these parameters in a single subject was defined as abnormality. Heterogeneity among studies investigating chronic cerebrospinal venous insufficiency detected by duplex sonography for the diagnosis of MS has been wide, with reported sensitivity ranging from $0 \%$ to $100 \%$. [146-154].

Unfortunately, B-mode anomalies of veins (intraluminal defects such as flaps, septa, membranes and valve defects) are difficult to detect with ultrasound. Several potential factors, both physiologic and technical, may affect the acquisition and interpretation of duplex sonograms (respiratory variability, heart rate cardiac rhythm, the hydration status of the patient, effects of head positioning, degree of external compression, pulse repetition frequency setting, crosssectional area measurement by B-mode versus color Doppler imaging, and sample volume placement during Doppler imaging).

Moreover, the innovation work of Zamboni is limited by the absence of a reference standard for intracranial evaluation, and they used a technology called Quality Doppler Profiles (QDP) that is not available on all ultrasonic scanning systems.

The difference in CCSVI prevalence between different published studies that use noninvasive or invasive imaging techniques underscored the central importance of a multimodal imaging approach for an optimal understanding of venous abnormalities indicative of CCSVI [155]. At the current state, researchers have been unable to define if CCSVI has a crucial role in multiple sclerosis pathogenesis and this point has raised serious objections to accept the hypothesis of
CCSVI as mechanism originating MS. Actually, additional researches on the subject are in progress and the results are still not determining. A 2013 study found out that CCSVI is uncommon both in MS patients and healthy controls, while narrowing of the cervical veins is equally common [156].

Lanzillo et al. observed a positive correlation between presence of CCSVI and the patients' age. However, no correlation was seen between CCSVI and clinical forms of MS, except for IJVs blocked flow that was more prevalent in progressive forms than in non-progressive forms [157]. Other authors also observed a positive correlation between age, disease duration and outflow block in the cervical veins [158]. The observation seems to confirm the hypothesis that venous abnormalities detectable in patients with MS, and in particular the flow block, may be a secondary and progressive impairment of the veins and not a primary causal factor.

Valvular IJV abnormalities are strongly associated with venous blood reflux in the intracranial veins, are more frequent in SP form and related to the EDSS class [159]. Pathologic studies identified vascular pathology in any layer of the jugular wall. Intraluminal defects are considered one the mechanisms causing a delay of jugular flow in patients with CCSVI.

In recent years, some authors have tried to study the ultra structure of extra cranial veins in patients with MS. The authors evaluated the expression of collagen type I and III, cytoskeletal protein and inflammatory markers (CD3 and CD8), in patients with CCSVI who underwent IJV reconstruction for restenosis after percutaneous transluminal angioplasty and in individuals without MS or other neurological diseases who underwent carotid endarterectomy with autologous external JV patch because of high-grade carotid stenosis. Collagen deposition was assessed by polarized light examination. The extra cranial veins of MS patients showed focal thickenings of the wall, with an altereted proportion of collagen I and III within the adventitia, due to a relative increase in type III collagen deposition. No differences in cytoscheletal protein and inflammatory marker expression were observed [160]. Pascolo et al. evaluated jugular tissue samples by both advanced synchrotron X-Ray Fluorescence (XRF) microscopy, and histological examination in two MS patients with CCSVI and in two control subjects. XRF analyses showed an increased Ca presence in the pathological samples, corresponding to rare and small basophilic bodies suggestive of micro calcifications. The samples of healthy controls showed no structural alterations at histological examination at XRF [161]. Recently Zamboni et al. studied the ultrastructure of IJV using a scanning electron microscopy (SEM) in 7 patients with CCSVI, underwent to vein open surgery and in 3 healthy controls who underwent to vein repair for traumatic causes. The veins of CCSVI patients showed partially detached endothelial cells, while the veins of healthy controls showed an intact endothelium, with regular arrangement of cells [162]. In conclusions, the IJVs of MS patients demonstrated changes in collagen and increased calcium content in adventitia, and disruption of endothelial layer, without coexistent inflammation. These alterations could be due to endothelial chronic stress secondary to altered hemodynamic. Moreover, the venous alterations as obstruction and/or reflux determine stasis and increased permeability to red blood cells and fibrinogen. The fibrinogen extravagated out of micro vessels polymerize to fibrin that, deposited outside the vessel, reduces tissue oxygenation. The fibrinogen can also induce local activation of myelin antigen-specific T-cells, and macrophage recruitment [163].

Therefore the link between venous circulation and immune response could be the extravasation of macromolecules into the interstitium 
of brain that can induce neuroinflammation, autoimmunity and demyelization and macrophage recruitment (Figure 2).

\section{MS and infectious pathogens}

Over the years, many studies have been published about MS geographical distribution and about the consistency of the hypothesis that environmental determinants should play a role in MS pathogenesis [3,4,164-168]. Among environmental factors, epidemiologic evidence and biochemical and immunological data from different populations suggest the involvement of an infective agent. The hypothesized mechanism is that an infectious pathogen, possibly with the concurrence of other inducing agents, causes a deregulation of lymphocyte function that leads to an uncontrolled immune reaction in the CNS, resulting; in early histological changes with an alteration of the blood-brain barrier that gradually evolve into the more typical CNS lesions [111,168-170]. Molecular mimicry between protein sequences from a particular microorganism and structural proteins present in the normal CNS is a possible explanation for autoimmune reactions in MS [171]. Many potential infective agents have been indicated as possible etiologic candidates, but no common interpretation of literature evidence has emerged [172,173]; the strongest associations are those with the gut microbiome [174-176], Rickettsia [177] and Chlamydia
[178-180] among bacteria and the Epstein-Barr [181,182] and herpes viruses among viruses [183-185]. Recently a chronic persisting venulitis affecting the cerebrospinal venous system, determined by Chlamydophila pneumonia respiratory infection observed in certain patients with MS, was hypothesized to lead to typical neural damage $[186,187]$.

\section{Vascular adverse effects of MS therapy}

The impact of the more-or-less recently introduced diseasemodifying drugs (DMDs) has changed patients 'outcome [188] but in some cases has shown negative effects at the cardiovascular level in various ways, whether directly or indirectly [44,189]. Systemic glucocorticoids have been associated with an increased risk of cardiovascular diseases including stroke, myocardial infarction, and atrial fibrillation [190,191]. Congestive heart failure was reported for both interferons and mitoxantrone, but data are scarce and causality is doubtful [192,193]. Mitoxantrone induces congestive heart failure, although it is usually asymptomatic [193]. Fingolimod has been associated with hypertension, bradycardia and atrioventricular blocks $[194,195]$ and, in a case report with ischemia of fingers, arterial vasospasm [196]. In contrast, the use of natalizumab was associated with lower cardiovascular risk factors [44].

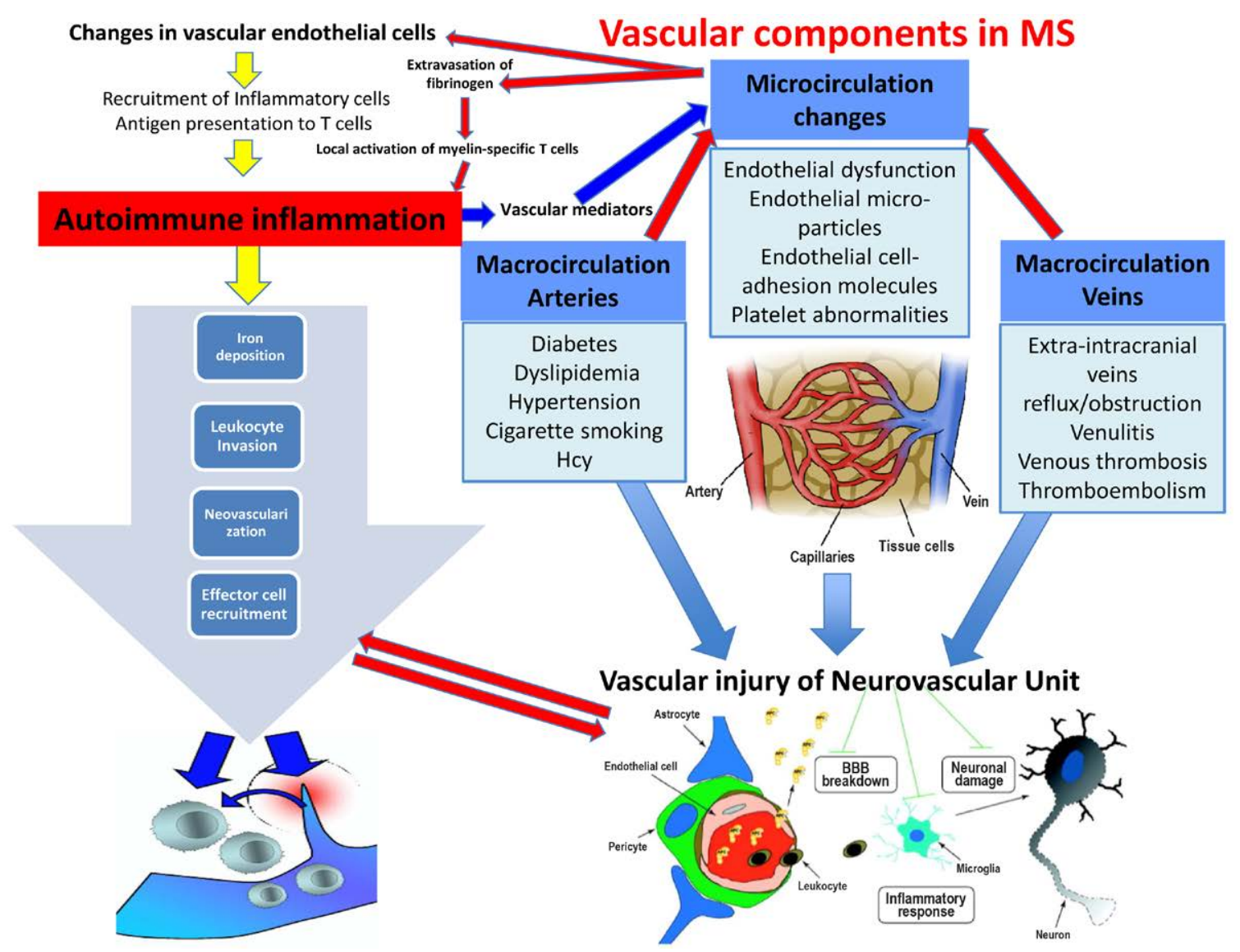

Figure 2: The immunological factors and vascular factors are connected. The scheme depicts the possible interplay between changes in macro and microcirculation and immunological factors. An altered macro-and microcirculation induces changes in endothelial cells that may determine cell-mediated immunity reactions: presenting antigens to lymphocytes, promoting inflammation in response to cytokines, and responding to oxidant injury. The autoimmune inflammation can determine iron deposition and increased leukocyte infiltration. In turn the vascular mediators released by immune cells, and the activated endothelium can cause neovascularization, lead to changes in microcirculation and recruitment of further effector cells. Venous alterations as obstruction and/or reflux determine stasis and increased permeability to red blood cells and fibrinogen. The fibrinogen extravasation reduce tissue oxygenation and induce macrophage recruitment and local activation of myelin antigen-specific T-cells. All factors affect the neurovascular unit. 
Interferon beta-1b is an immunomodulatory drug used for a treatment of several diseases including MS. In 1993 recombinant interferon beta- $1 \mathrm{~b}$ (Betaseron) was approved for the treatment of exacerbations of multiple sclerosis. The drug's effectiveness was modest, with $30 \%$ of relapses and the appearance of side effects such as local irritation, and a flu-like syndrome [197,198].

\section{Conclusions}

The etiology of MS and neurologic involvement are still unknown and the clinical course extremely variable. It can take various forms, including those relapsing and progressive ones. Each of these forms involves numerous disease mechanisms, and as such, MS is a multifactorial disease.

The typical characteristics of MS pathophysiology include inflammatory and vascular factors that lead to the molecular interactions between cellular components (brain endothelial cells, astrocytes, pericytes, inflammatory cells, and neurons) and myelin components, resulting in increased blood-brain barrier permeability, neurovascular uncoupling and dysfunction and neuronal damage.

This review focuses on vascular abnormalities that have been described in MS. Recent hypotheses and evidence suggest that vascular components may be initiating triggers for neuronal pathology and subsequent neurological manifestations of the disease.

Patients with MS have more cardiovascular risk factors, an increased risk for ischemic stroke and an increased risk of venous thrombosis and pulmonary embolism. Vascular comorbidities are common in MS and adversely influence disability. There is evidence suggesting that MS patients are more susceptible to cardiovascular risk factors than healthy controls.

Several studies have demonstrated regional cerebral perfusion abnormalities in MS compared to controls. The relationship between the disturbances in cerebral venous outflow and neurological disorders remains an open issue that requires further studies.

The debate on whether vascular events are the primary cause of neurological diseases or rather a mere participant recruited from a primary neuronal origin of pathology is still open.

The high degree of comorbidity between vascular disease and MS suggests that vascular pathology may be an important factor causing neuronal dysfunction or degeneration in multiple sclerosis.

In our opinion, this review is useful to shed light on a hot topic in which literature is still lacking.

The results in literature are not always consistent, both for the frequency of association between vascular disease and neurological disease, both for the relationship between vascular disease, cerebral damage and clinical disability. Several studies are mostly "case-control" and studies on population are few. Furthermore, the authors of studies do not always come from centers with expertise in epidemiological assessment. It is possible that many of the changes reported in the literature are a result of bias in the interpretation or effects of the disease itself, or activation of the immune system or of drug treatment.

Therefore, more rigorous epidemiological and pathophysiological studies are needed to verify the biological plausibility between vascular damage and demyelinating-neurodegenerative diseases.

\section{Acknowledgement}

This work was supported by a research grant from the Italian Ministry for Education University and Research in the framework of PRIN (2010XE5L2R_004).
The funders had no role in study design, data collection and analysis, decision to publish, or preparation of the manuscript. The authors thank Dr. Marianna Malgieri for the editing of the manuscript.

\section{References}

1. Noseworthy JH, Lucchinetti C, Rodriguez M, Weinshenker BG (2000) Multiple sclerosis. N Engl J Med 343: 938-952.

2. Ramagopalan SV, Dobson R, Meier UC, Giovannoni G (2010) Multiple sclerosis: risk factors, prodromes, and potential causal pathways. Lancet Neurol 9: 727-739.

3. Ebers GC, Sadovnick AD (1993) The geographic distribution of multiple sclerosis: a review. Neuroepidemiology 12: 1-5.

4. Kurtzke JF (2000) Multiple sclerosis in time and space-geographic clues to cause. J Neurovirol 6 Suppl 2: S134-140.

5. Charcot J (1868) Histologie de la sclerose en plaques. Gaz Hopit Civilis Milit 4: $554-566$

6. Adams CW (1988) Perivascular iron deposition and other vascular damage in multiple sclerosis. J Neurol Neurosurg Psychiatry 51: 260-265.

7. Fog $T$ (1965) The topography of plaques in multiple sclerosis with special reference to cerebral plaques. Acta Neurol Scand Suppl 15: 1-161.

8. Tracy J, Putnam MD (1933) The pathogenesis of multiple sclerosis, a possible vascular factor. N Engl J Med 209: 786-790.

9. Tettey P, Simpson S Jr, Taylor BV, van der Mei IA (2014) Vascula comorbidities in the onset and progression of multiple sclerosis. J Neurol Sci 347: 23-33

10. Karmon $Y$, Ramanathan M, Minagar A, Zivadinov R, Weinstock-Guttman B (2012) Arterial, venous and other vascular risk factors in multiple sclerosis. Neurol Res 34: 754-760.

11. Christiansen CF, Christensen S, Farkas DK, Miret M, Sørensen HT et al (2010) Risk of arterial cardiovascular diseases in patients with multiple sclerosis: a population-based cohort study. Neuroepidemiology 35: 267-274.

12. Moccia M, Lanzillo R, Palladino R2,3, Maniscalco GT, et al. (2015) The Framingham cardiovascular risk score in multiple sclerosis. Eur $\mathrm{J}$ Neurol 22 1176-1183.

13. Sternberg $Z$, Leung $C$, Sternberg D, Li F, Karmon $Y$, et al (2013) The prevalence of the classical and non-classical cardiovascular risk factors in multiple sclerosis patients. CNS Neurol Disord Drug Targets 12: 104-111.

14. Marrie RA, Reider N, Cohen J, Stuve O, Trojano M, et al. (2015) A systematic review of the incidence and prevalence of cardiac, cerebrovascular, and peripheral vascular disease in multiple sclerosis. Mult Scler 21: 318-331.

15. Kappus N, Weinstock-Guttman B, Hagemeier J, Kennedy C, Melia R, et al (2015) Cardiovascular risk factors are associated with increased lesion burden and brain atrophy in multiple sclerosis. J Neurol Neurosurg Psychiatry.

16. Munger KL, Bentzen J, Laursen B, Stenager E, Koch-Henriksen N, et al (2013) Childhood body mass index and multiple sclerosis risk: a long-term cohort study. Mult Scler 19: 1323-1329.

17. Pilutti LA, Dlugonski D, Pula JH, Mot RW (2012) Weight status in persons with multiple sclerosis: implications for mobility outcomes. J Obes 2012: 868256.

18. Pinhas-Hamiel O, Livne M, Harari G, Achiron A (2015) Prevalence of overweight, obesity and metabolic syndrome components in multiple sclerosis patients with significant disability. Eur J Neurol.

19. Allen NB, Lichtman JH, Cohen HW, Fang J, Brass LM, et al. (2008) Vascular disease among hospitalized multiple sclerosis patients. Neuroepidemiology 30: 234-238.

20. Khurana SR, Bamer AM, Turner AP, Wadhwani RV, Bowen JD, et al. (2009) The prevalence of overweight and obesity in veterans with multiple sclerosis. Am J Phys Med Rehabil 88: 83-91.

21. Tettey P, Simpson S Jr, Taylor B, Blizzard L, Ponsonby AL, et al. (2014) An adverse lipid profile is associated with disability and progression in disability, in people with MS. Mult Scler 20: 1737-1744.

22. Lucas RM, Ponsonby AL, Dear K, Valery PC, Pender MP, et al. (2011) Sun exposure and vitamin $\mathrm{D}$ are independent risk factors for CNS demyelination. Neurology 76: 540-548. 
23. Munger KL, Levin LI, Hollis BW, Howard NS, Ascherio A (2006) Serum 25-hydroxyvitamin D levels and risk of multiple sclerosis. JAMA 296: 28322838.

24. van der Mei IA, Ponsonby AL, Dwyer T, Blizzard L, Simmons R, et al. (2003) Past exposure to sun, skin phenotype, and risk of multiple sclerosis: casecontrol study. BMJ 327: 316 .

25. Weinstock-Guttman B, Mehta BK, Ramanathan M, Karmon Y, Henson LJ, et al. (2012) Vitamin D and multiple sclerosis. Neurologist 18: 179-183.

26. Kappus N, Weinstock-Guttman B, Hagemeier J, Kennedy C, Melia R, et al. (2016) Cardiovascular risk factors are associated with increased lesion burden and brain atrophy in multiple sclerosis. J Neurol Neurosurg Psychiatry 87:181-187.

27. McGreevy C, Williams D (2011) New insights about vitamin D and cardiovascular disease: a narrative review. Ann Intern Med 155: 820-826.

28. Ascherio A, Munger KL, Simon KC (2010) Vitamin D and multiple sclerosis. Lancet Neurol 9: 599-612.

29. Hayes CE, Nashold FE, Spach KM, Pedersen LB (2003) The immunological functions of the vitamin D endocrine system. Cell Mol Biol (Noisy-le-grand) 49: 277-300.

30. Lemire JM, Archer DC (1991) , 25-dihydroxyvitamin D3 prevents the in vivo induction of murine experimental autoimmune encephalomyelitis. J Clin Invest 87: 1103-1107.

31. Cantorna MT, Hayes CE, DeLuca HF (1996) 25-Dihydroxyvitamin D3 reversibly blocks the progression of relapsing encephalomyelitis, a model of multiple sclerosis. Proc Natl Acad Sci USA 93: 7861-7864.

32. Hayes CE, Nashold FE, Hoag KA, Goverman J, Hayes CE (2001) Rag-1dependent cells are necessary for ,25-dihydroxyvitamin $\mathrm{D}(3)$ prevention of experimental autoimmune encephalomyelitis. J Neuroimmunol 119:16-29.

33. Viglietta V, Baecher-Allan C, Weiner HL, Hafler DA (2004) Loss of functional suppression by $\mathrm{CD}^{+} \mathrm{CD} 25^{+}$regulatory $\mathrm{T}$ cells in patients with multiple sclerosis. J Exp Med 199: 971-979.

34. Hauser SL, Weiner HL, Che M, Shapiro ME, Gilles F, et al. (1984) Prevention of experimental allergic encephalomyelitis (EAE) in the SJL/J mouse by whole body ultraviolet irradiation. J Immunol 132: 1276-1281.

35. Aubin F (2003) Mechanisms involved in ultraviolet light-induced immunosuppression. Eur J Dermatol 13: 515-523.

36. Gale CR, Martyn CN (1995) Migrant studies in multiple sclerosis. Prog Neurobiol 47: 425-448.

37. Bechtold S, Blaschek A, Raile K, Dost A, Freiberg C, et al. (2014) Higher relative risk for multiple sclerosis in a pediatric and adolescent diabetic population: analysis from DPV database. Diabetes Care 37: 96-101.

38. Marrosu MG, Motzo C, Murru R, Lampis R, Costa G, et al. (2004) The coinheritance of type 1 diabetes and multiple sclerosis in Sardinia cannot be explained by genotype variation in the HLA region alone. Hum Mol Genet 13 : 2919-2924.

39. Pitzalis M, Zavattari P, Murru R, Deidda E, Zoledziewska M, et al. (2008) Genetic loci linked to type 1 diabetes and multiple sclerosis families in Sardinia. BMC Med Genet 9: 3

40. Fleming ST, Blake RL Jr (1994) Patterns of comorbidity in elderly patients with multiple sclerosis. J Clin Epidemiol 47: 1127-1132.

41. Hussein WI, Reddy SS (2006) Prevalence of diabetes in patients with multiple sclerosis. Diabetes Care 29: 1984-1985.

42. Kang JH, Chen $\mathrm{YH}$, Lin $\mathrm{HC}$ (2010) Comorbidities amongst patients with multiple sclerosis: a population-based controlled study. Eur J Neurol 17: 1215-1219.

43. Marrie RA, Yu BN, Leung S, Elliott L, Caetano P, et al. (2012) Rising prevalence of vascular comorbidities in multiple sclerosis: validation of administrative definitions for diabetes, hypertension, and hyperlipidemia. Mult Scler 18: 1310-1319.

44. Sternberg Z, Leung C, Sternberg D, Yu J, Hojnacki D (2014) Disease modifying therapies modulate cardiovascular risk factors in patients with multiple sclerosis. Cardiovasc Ther 32: 33-39.

45. Marrie RA, Rudick R, Horwitz R, Cutter G, Tyry T, et al. (2010) Vascular comorbidity is associated with more rapid disability progression in multiple sclerosis. Neurology 74:1041-1047.
46. Marrie RA, Cutter G, Tyry T (2011) Substantial adverse association of visual and vascular comorbidities on visual disability in multiple sclerosis. Mult Scler $17: 1464-1471$.

47. Pinhas-Hamiel O, Livne M, Harari G, Achiron A (2015) Prevalence of overweight, obesity and metabolic syndrome components in multiple sclerosis patients with significant disability. Eur J Neurol 22:1275-1279.

48. Lavela SL, Prohaska TR, Furner S, Weaver FM (2012) Chronic diseases in male veterans with multiple sclerosis. Prev Chronic Dis 9: E55.

49. Giubilei F, Antonini G, Di Legge S, Sormani MP, Pantano P, et al. (2002) Blood cholesterol and MRI activity in first clinical episode suggestive of multiple sclerosis. Acta Neurol Scand 106: 109-112.

50. Jamroz-Wisniewska A, Beltowski J, Stelmasiak Z, Bartosik-Psujek H (2009) Paraoxonase 1 activity in different types of multiple sclerosis. Mult Scler 15 399-402.

51. Salemi G, Gueli MC, Vitale F, Battaglieri F, Guglielmini E, et al. (2010) Blood lipids, homocysteine, stress factors, and vitamins in clinically stable multiple sclerosis patients. Lipids Health Dis 18: 9-19.

52. Palavra F, Marado D, Mascarenhas-Melo F, Sereno J, Teixeira-Lemos E, et al. (2013) New markers of early cardiovascular risk in multiple sclerosis patients: oxidized-LDL correlates with clinical staging. Dis Markers 34: 341-348.

53. Kappos L, Moeri D, Radue EW, Schoetzau A, Schweikert K, et al. (1999) Predictive value of gadolinium-enhanced magnetic resonance imaging for relapse rate and changes in disability or impairment in multiple sclerosis: a meta-analysis. Gadolinium MRI Meta-analysis Group. Lancet 353: 964-969.

54. He J, Grossman RI, Ge Y, Mannon LJ (2001) Enhancing patterns in multiple sclerosis: evolution and persistence. AJNR Am J Neuroradiol 22: 664-669.

55. Weinstock-Guttman B, Zivadinov R, Mahfooz N, Carl E, Drake A, et al. (2011) Serum lipid profiles are associated with disability and MRI outcomes in multiple sclerosis. J Neuroinflammation 8: 127.

56. Dietschy JM, Turley SD (2004) Thematic review series: brain Lipids. Cholestero metabolism in the central nervous system during early development and in the mature animal. J Lipid Res 45: 1375-1397.

57. Leoni V, Caccia C (2011) Oxysterols as biomarkers in neurodegenerative diseases. Chem Phys Lipids 164: 515-524.

58. Fessler MB, Parks JS (2011) Intracellular lipid flux and membrane microdomain as organizing principles in inflammatory cell signaling. J Immunol 187: 15291535

59. Weinstock-Guttman B, Zivadinov R, Horakova D, Havrdova E, Qu J, et al (2013) Lipid profiles are associated with lesion formation over 24 months in interferon- $ß$ treated patients following the first demyelinating event. J Neurol Neurosurg Psychiatry 84:1186-1191.

60. Swank RL, Goodwin J (2003) Review of MS patient survival on a Swank low saturated fat diet. Nutrition 19: 161-162.

61. Swank RL, Goodwin JW (2003) How saturated fats may be a causative factor in multiple sclerosis and other diseases. Nutrition 19: 478.

62. Hernán MA, Olek MJ, Ascherio A (2001) Cigarette smoking and incidence of multiple sclerosis. Am J Epidemiol 154: 69-74.

63. Hernán MA, Jick SS, Logroscino G, Olek MJ, Ascherio A, et al. (2005) Cigarette smoking and the progression of multiple sclerosis. Brain 128: 1461-1465.

64. Villard-Mackintosh L, Vessey MP (1993) Oral contraceptives and reproductive factors in multiple sclerosis incidence. Contraception 47: 161-168.

65. Thorogood M, Hannaford PC (1998) The influence of oral contraceptives on the risk of multiple sclerosis. Br J Obstet Gynaecol 105: 1296-1299.

66. Hedström AK, Bäärnhielm M, Olsson T, Alfredsson L (2009) Tobacco smoking but not Swedish snuff use, increases the risk of multiple sclerosis. Neurology 73: 696-701.

67. Riise T, Nortvedt MW, Ascherio A (2003) Smoking is a risk factor for multiple sclerosis. Neurology 61: 1122-1124.

68. Sundström P, Nyström L, Hallmans G (2008) Smoke exposure increases the risk for multiple sclerosis. Eur J Neurol 15: 579-583.

69. Bass NH (1968) Pathogenesis of myelin lesions in experimental cyanide encephalopathy. A microchemical study. Neurology 18: 167-177. 
70. Lessell S (1971) Experimental cyanide optic neuropathy. Arch Ophthalmol 86: 194-204.

71. Chen JL, Wei L, Bereczki D, Hans FJ, Otsuka T, et al. (1995) Nicotine raises the influx of permeable solutes across the rat blood-brain barrier with little or no capillary recruitment. J Cereb Blood Flow Metab 15: 687-698.

72. Sopori ML, Kozak W (1998) Immunomodulatory effects of cigarette smoke. J Neuroimmunol 83: 148-156.

73. Francus T, Klein RF, Staiano-Coico L, Becker CG, Siskind GW (1988) Effects of tobacco glycoprotein (TGP) on the immune system. II. TGP stimulates the proliferation of human $T$ cells and the differentiation of human $B$ cells into Ig secreting cells. J Immunol 140: 1823-1829.

74. Rejdak K, Eikelenboom MJ, Petzold A, Thompson EJ, Stelmasiak Z, et al. (2004) CSF nitric oxide metabolites are associated with activity and progression of multiple sclerosis. Neurology 63: 1439-1445.

75. Healy BC, Ali EN, Guttmann CR, Chitnis T, Glanz BI, et al. (2009) Smoking and disease progression in multiple sclerosis. Arch Neurol 66: 858-864.

76. Handel AE, Williamson AJ, Disanto G, Dobson R, Giovannoni G, et al. (2011) Smoking and multiple sclerosis: an updated meta-analysis. PLoS One 6: e16149.

77. Hankey GJ, Eikelboom JW (1999) Homocysteine and vascular disease. Lancet 354: 407-413.

78. Zhu Y, He ZY, Liu HN (2011) Meta-analysis of the relationship between homocysteine, vitamin B12, folate and multiple sclerosis. J Clin Neurosci 18 933-938.

79. Ansari R, Mahta A, Mallack E2, Luo JJ (2014) Hyperhomocysteinemia and neurologic disorders: a review. J Clin Neurol 10: 281-288.

80. Aksungar FB, Topkaya AE, Yildiz Z, Sahin S, Turk U (2008) Coagulation status and biochemical and inflammatory markers in multiple sclerosis. J Clin Neurosci 15: 393-397.

81. Ho PI, Ortiz D, Rogers E, Shea TB (2002) Multiple aspects of homocysteine neurotoxicity: glutamate excitotoxicity, kinase hyperactivation and DNA damage. J Neurosci Res 70: 694-702.

82. Triantafyllou N, Evangelopoulos ME, Kimiskidis VK, Kararizou E, Boufidou F, et al. (2008) Increased plasma homocysteine levels in patients with multiple sclerosis and depression. Ann Gen Psychiatry 7: 17.

83. Vrethem M, Mattsson E, Hebelka H, Leerbeck K, Osterberg A, et al. (2003) Increased plasma homocysteine levels without signs of vitamin B12 deficiency in patients with multiple sclerosis assessed by blood and cerebrospinal fluid homocysteine and methylmalonic acid. Mult Scler 9: 239-245.

84. Ramsaransing GS, Fokkema MR, Teelken A, Arutjunyan AV, Koch M, et al. (2006) Plasma homocysteine levels in multiple sclerosis. J Neurol Neurosurg Psychiatry 77: 189-192.

85. Río J, Montalban J, Tintoré M, Codina A, Malinow MR (1994) Serum homocysteine levels in multiple sclerosis. Arch Neurol 51: 1181.

86. Russo C, Morabito F, Luise F, Piromalli A, Battaglia L, et al. (2008) Hyperhomocysteinemia is associated with cognitive impairment in multiple sclerosis. J Neurol 255: 64-69.

87. Moghaddasi M, Mamarabadi M, Mohebi N, Razjouyan H, Aghaei M (2013) Homocysteine, vitamin B12 and folate levels in Iranian patients with Multiple Sclerosis: a case control study. Clin Neurol Neurosurg 115: 1802-1805.

88. Koch-Henriksen N, Brønnum-Hansen H, Stenager E (1998) Underlying cause of death in Danish patients with multiple sclerosis: results from the Danish Multiple Sclerosis Registry. J Neurol Neurosurg Psychiatry 65: 56-59.

89. Hirst C, Swingler R, Compston DA, Ben-Shlomo Y, Robertson NP (2008) Survival and cause of death in multiple sclerosis: a prospective populationbased study. J Neurol Neurosurg Psychiatry 79: 1016-1021.

90. Marrie RA, Horwitz R, Cutter G, Tyry T, Campagnolo D, et al. (2009) Comorbidity delays diagnosis and increases disability at diagnosis in MS Neurology 72: 117-124.

91. Ruiz-Irastorza G, Crowther M, Branch W, Khamashta MA (2010) Antiphospholipid syndrome. Lancet 376: 1498-1509.

92. Peterson LK, Fujinami RS (2007) Inflammation, demyelination, neurodegeneration and neuroprotection in the pathogenesis of multiple sclerosis. J Neuroimmunol 184: 37-44.
93. Brück W (2005) The pathology of multiple sclerosis is the result of focal inflammatory demyelination with axonal damage. J Neurol 252 Suppl 5: v3-9.

94. Slawta JN, Wilcox AR, McCubbin JA, Nalle DJ, Fox SD, et al. (2003) Health behaviors, body composition, and coronary heart disease risk in women with multiple sclerosis. Arch Phys Med Rehabil 84: 1823-1830.

95. Marrie R, Horwitz R, Cutter G, Tyry T, Campagnolo D, et al. (2009) High frequency of adverse health behaviors in multiple sclerosis. Mult Scler 15: $105-113$

96. Ross R (1999) Atherosclerosis-an inflammatory disease. N Engl J Med 340 $115-126$.

97. O'Keefe JH, Carter MD, Lavie CJ (2009) Primary and secondary prevention of cardiovascular diseases: a practical evidence-based approach. Mayo Clin Proc 84: 741-757

98. Jadidi E, Mohammadi M, Moradi T (2013) High risk of cardiovascular diseases after diagnosis of multiple sclerosis. Mult Scler 19: 1336-1340.

99. Tseng CH, Huang WS, Lin CL, Chang YJ. (2015) Increased risk of ischaemic stroke among patients with multiple sclerosis. Eur J Neurol 22: 500-506.

100. Roshanisefat H, Bahmanyar S, Hillert J, Olsson T, Montgomery S (2014) Multiple sclerosis clinical course and cardiovascular disease risk - Swedish cohort study. Eur J Neurol 21: 1353-1353e88.

101. Lindegard B (1985) Diseases associated with multiple sclerosis and epilepsy. A population cohort study of 1,59,200 middle-aged, urban, native Swedes observed over 10 years (1970-79). Acta Neurol Scand 71: 267-277.

102. Brønnum-Hansen H, Koch-Henriksen N, Stenager E (2004) Trends in survival and cause of death in Danish patients with multiple sclerosis. Brain 127: 844850 .

103. Marrie RA, Yu BN, Leung S, Elliott L, Caetano P, et al. (2013) Prevalence and incidence of ischemic heart disease in multiple sclerosis: A population-based validation study. Mult Scler Relat Disord 2: 355-361.

104.Zöller B, Li X, Sundquist J, Sundquist K (2012) Risk of pulmonary embolism in patients with autoimmune disorders: a nationwide follow-up study from Sweden. Lancet 379: 244-249.

105. Ramagopalan SV, Wotton CJ, Handel AE, Yeates D, Goldacre MJ (2011) Risk of venous thromboembolism in people admitted to hospital with selected immune-mediated diseases: record-linkage study. BMC Med 9: 1.

106. Christensen S, Farkas DK, Pedersen L, Miret M, Christiansen CF, et al. (2012) Multiple sclerosis and risk of venous thromboembolism: a population-based cohort study. Neuroepidemiology 38: 76-83.

107. Arpaia G, Bavera PM, Caputo D, Mendozzi L, Cavarretta R, et al. (2010) Risk of deep venous thrombosis (DVT) in bedridden or wheelchair-bound multiple sclerosis patients: a prospective study. Thromb Res 125: 315-317.

108. Umpleby $H$ (2012) Autoimmune disorders increase the risk of developing pulmonary embolism. Thorax 67: 907-912.

109. Peeters PJ, Bazelier MT, Uitdehaag BM, Leufkens HG, De Bruin ML, et al. (2014) The risk of venous thromboembolism in patients with multiple sclerosis: the Clinical Practice Research Datalink. J Thromb Haemost 12: 444-451.

110. Kaufman J, Khatri BO, Riendl P (1988) Are patients with multiple sclerosis protected from thrombophlebitis and pulmonary embolism? Chest 94: 9981001.

111. Poser CM (1986) Pathogenesis of multiple sclerosis. A critical reappraisal Acta Neuropathol 71: 1-10.

112. Rae-Grant AD, Wong C, Bernatowicz R, Fox RJ (2014) Observations on the brain vasculature in multiple sclerosis: A historical perspective. Mult Scler Relat Disord 3: 156-162.

113. Werner P, Pitt D, Raine CS (2001) Multiple sclerosis: altered glutamate homeostasis in lesions correlates with oligodendrocyte and axonal damage. Ann Neurol 50: 169-180.

114. Minagar A, Jy W, Jimenez JJ, Alexander JS (2006) Multiple sclerosis as a vascular disease. Neurol Res 28: 230-235.

115. Frohman EM, Racke MK, Raine CS (2006) Multiple sclerosis-the plaque and its pathogenesis. N Engl J Med 354: 942-955.

116. Haider L, Fischer MT, Frischer JM, Bauer J, Höftberger R, et al. (2011) Oxidative damage in multiple sclerosis lesions. Brain 134: 1914-1924. 
117. van Horssen J, Witte ME, Schreibelt G, de Vries HE (2011) Radical changes in multiple sclerosis pathogenesis. Biochim Biophys Acta 1812: 141-150.

118. Yanagisawa M, Kurihara H, Kimura S, Tomobe Y, Kobayashi M, et al. (1988) A novel potent vasoconstrictor peptide produced by vascular endothelial cells. Nature 332: 411-415.

119. D'haeseleer M, Beelen R, Fierens Y, Cambron M, Vanbinst AM, et al. (2013) Cerebral hypoperfusion in multiple sclerosis is reversible and mediated by endothelin-1. Proc Natl Acad Sci U S A 110: 5654-5658.

120. Jankowska-Lech I, Terelak-Borys B, Grabska-Liberek I, Palasik W, Bik W, et al. (2015) Decreased endothelin-1 plasma levels in multiple sclerosis patients: a possible factor of vascular dysregulation?. Med Sci Monit 2: 1066-1071

121.Zivadinov R, Weinstock-Guttman B, Pirko I (2011) Iron deposition and inflammation in multiple sclerosis. Which one comes first? BMC Neuroscience 20: 60-65.

122. Hammond KE, Metcalf M, Carvajal L, Okuda DT, Srinivasan R, et al. (2008) Quantitative in vivo magnetic resonance imaging of multiple sclerosis at 7 Tesla with sensitivity to iron. Ann Neurol 64: 707-713.

123. Hagemeier J, Weinstock-Guttman B, Heininen-Brown M, Poloni GU, Bergsland N, et al. (2013) Gray matter SWI-filtered phase and atrophy are linked to disability in MS. Front Biosci (Elite Ed) 5: 525-532.

124. Kira J (2014) (Disease concept, etiology and mechanisms of multiple sclerosis). Nihon Rinsho 72: 1884-1894.

125.Zhou Y, Taylor B, van der Mei I, Stewart N, Charlesworth J, et al. (2015) Genetic variation in PBMC-produced IFN- $y$ and TNF- $\alpha \pm$ associations with relapse in multiple sclerosis. J Neurol Sci 349: 40-44.

126. Hashioka S, McGeer EG, Miyaoka T, Wake R, Horiguchi J, et al. (2015) Interferon-y-induced neurotoxicity of human astrocytes. CNS Neurol Disord Drug Targets 14: 251-256.

127. Sheremata WA, Jy W, Horstman LL, Ahn YS, Alexander JS, et al. (2008) Evidence of platelet activation in multiple sclerosis. J Neuroinflammation 5: 27.

128. Wuerfel J, Paul F, Zipp F (2007) Cerebral blood perfusion changes in multiple sclerosis. J Neurol Sci 259: 16-20.

129. Wuerfel J, Bellmann-Strobl J, Brunecker $\mathrm{P}$, Aktas $\mathrm{O}$, McFarland $\mathrm{H}$, et al. (2004) Changes in cerebral perfusion precede plaque formation in multiple sclerosis: a longitudinal perfusion MRI study. Brain 127: 111-119.

130. Rosso C, Remy P, Creange A, Brugieres P, Cesaro P, et al. (2006) Diffusionweighted MR imaging characteristics of an acute strokelike form of multiple sclerosis. AJNR Am J Neuroradiol 27: 1006-1008.

131. Law M, Saindane AM, Ge Y, Babb JS, Johnson G, et al. (2004) Microvascular abnormality in relapsing-remitting multiple sclerosis: perfusion MR imaging findings in normal-appearing white matter. Radiology 231: 645-652.

132. Inglese M, Park SJ, Johnson G, Babb JS, Miles L, et al. (2007) Deep gray matter perfusion in multiple sclerosis: dynamic susceptibility contrast perfusion magnetic resonance imaging at 3 T. Arch Neurol 64: 196-202.

133. Varga AW, Johnson G, Babb JS, Herbert J, Grossman RI, et al. (2009) White matter hemodynamic abnormalities precede sub-cortical gray matter changes in multiple sclerosis. J Neurol Sci 282: 28-33.

134. Inglese M, Adhya S, Johnson G, Babb JS, Miles L, et al. (2008) Perfusion magnetic resonance imaging correlates of neuropsychological impairment in multiple sclerosis. J Cereb Blood Flow Metab 28: 164-171.

135. Saindane AM, Law M, Ge Y, Johnson G, Babb JS, et al. (2007) Correlation of diffusion tensor and dynamic perfusion MR imaging metrics in normalappearing corpus callosum: support for primary hypoperfusion in multiple sclerosis. AJNR Am J Neuroradiol 28: 767-772.

136. Holland CM, Charil A, Csapo I, Liptak Z, Ichise M, et al. (2012) The relationship between normal cerebral perfusion patterns and white matter lesion distribution in ,249 patients with multiple sclerosis. J Neuroimaging 22: 129-136.

137. Cruveilhier J (1829-1842) Anatomie pathologique du corps humain. Bailliere, Paris, France.

138. Reindfleisch $E$ (1863) Histologisches detail zu der grauen degeneration von gehirn und rueckenmark. Arch Path Anat Physiol Klin Med 26: 474-483.

139. Tracy J, Putnam MD (1937) Evidences of vascular occlusion in multiple sclerosis and "encephalomyelitis". Arch Neur Psych 37: 1298-1321.
140. Fog T (1963) On the vessel-plaque relations in the brain in multiple sclerosis. Acta Psychiat Neurol Scand 39: 257-262

141. Allen IV (1981) The pathology of multiple sclerosis-fact, fiction and hypothesis Neuropathol Appl Neurobiol 7: 169-182.

142.Zamboni $P$ (2006) The big idea: iron-dependent inflammation in venous disease and proposed parallels in multiple sclerosis. J R Soc Med 99: 589593.

143. Ge Y, Zohrabian VM, Osa EO, Xu J, Jaggi H, et al. (2009) Diminished visibility of cerebral venous vasculature in multiple sclerosis by susceptibility-weighted imaging at 3.0 Tesla. J Magn Reson Imaging 29: 1190-1194.

144.Ge Y, Law M, Johnson G, Herbert J, Babb JS, et al. (2005) Dynamic susceptibility contrast perfusion MR imaging of multiple sclerosis lesions: characterizing hemodynamic impairment and inflammatory activity. AJNR Am J Neuroradiol 26: 1539-1547.

145. Singh AV, Zamboni P (2009) Anomalous venous blood flow and iron deposition in multiple sclerosis. J Cereb Blood Flow Metab 29: 1867-1878.

146.Zamboni P, Galeotti R, Menegatti E, Malagoni AM, Tacconi G, et al. (2009) Chronic cerebrospinal venous insufficiency in patients with multiple sclerosis. J Neurol Neurosurg Psychiatry 80: 392-399.

147. Fox RJ, Rae-Grant A (2011) Chronic cerebrospinal venous insufficiency: have we found the cause and cure of MS? Neurology 77: 98-100.

148. Doepp F, Paul F, Valdueza JM, Schmierer K, Schreiber SJ (2010) No cerebrocervical venous congestion in patients with multiple sclerosis. Ann Neurol 68: 173-183

149.Zamboni P, Morovic S, Menegatti E, Viselner G, Nicolaides AN (2011) Screening for chronic cerebrospinal venous insufficiency (CCSVI) using ultrasound-recommendations for a protocol. Int Angiol 30: 571-597.

150.Laupacis A, Lillie E, Dueck A, Straus S, Perrier L, et al. (2011) Association between chronic cerebrospinal venous insufficiency and multiple sclerosis: a meta-analysis. CMAJ 183: E1203-1212.

151.Zamboni P, Menegatti E, Galeotti R, Malagoni AM, Tacconi G, et al. (2009) The value of cerebral Doppler venous haemodynamics in the assessment of multiple sclerosis. J Neurol Sci 282: 21-27.

152. Sundström P, Wåhlin A, Ambarki K, Birgander R, Eklund A, et al. (2010) Venous and cerebrospinal fluid flow in multiple sclerosis: a case-control study. Ann Neurol 68: 255-259.

153. Baracchini C, Perini P, Calabrese M, Causin F, Rinaldi F, et al. (2011) No evidence of chronic cerebrospinal venous insufficiency at multiple sclerosis onset. Ann Neurol 69: 90-99.

154. Mayer CA, Pfeilschifter W, Lorenz MW, Nedelmann M, Bechmann I, et al. (2011) The perfect crime? CCSVI not leaving a trace in MS. J Neurol Neurosurg Psychiatry 82: 436-440.

155. Dolic K, Siddiqui AH, Karmon Y, Marr K, Zivadinov R. (2013) The role of noninvasive and invasive diagnostic imaging techniques for detection of extracranial venous system anomalies and developmental variants. BMC Med.

156. Comi G, Battaglia MA, Bertolotto A, Del Sette M, Ghezzi A, et al. (2013) CoSMo Collaborative Study Group. Observational case-control study of the prevalence of chronic cerebrospinal venous insufficiency in multiple sclerosis: results from the CoSMo study. Mult Scler 19:1508-1517.

157. Lanzillo R, Mancini M, Liuzzi R, Di Donato O, Salvatore E, et al. (2013) Chronic cerebrospinal venous insufficiency in multiple sclerosis: a highly prevalent age-dependent phenomenon. BMC Neurol.

158. Ciciarello F, Mandolesi S, Galeandro AI, Marceca A, Rossi M, et al. (2014) Age-related vascular differences among patients suffering from multiple sclerosis. Curr Neurovasc Res 11: 23-30.

159. Ciccone MM, Galeandro AI, Scicchitano P, Zito A, Gesualdo M et al. (2012) Multigate quality Doppler profiles and morphological/hemodynamic alterations in multiple sclerosis patients. Curr Neurovasc Res 9: 120-127.

160.Pascolo L, Gianoncelli A, Rizzardi C, Tisato V, Salomé M, et al. (2014) Calcium micro-depositions in jugular truncular venous malformations revealed by Synchrotron-based XRF imaging. Sci Rep 4: 6540 .

161.Zamboni P, Tisato V, Menegatti E, Mascoli F, Gianesini S, et al. (2014) Ultrastructure of internal jugular vein defective valves. Phlebology 30: 644647. 
Citation: Caprio MG, Russo C, Giugliano A, Ragucci M, Mancini M (2016) Vascular Disease in Patients with Multiple Sclerosis: A Review. J Vasc Med Surg 4: 259. doi:10.4172/2329-6925.1000259

162. Ryu JK, Petersen MA, Murray SG, Baeten KM, Meyer-Franke A et al. (2015) Blood coagulation protein fibrinogen promotes autoimmunity and demyelination via chemokine release and antigen presentation. Nat Commun.

163. Acheson ED, Bachrach CA, Wright FM (1960) Some comments on the relationship of the distribution of multiple sclerosis to latitude, solar radiation, and other variables. Acta Psychiatr Scand Suppl 35: 132-147.

164. Kurtzke JF, Hyllested K (1987) Multiple sclerosis in the Faroe Islands. III. An alternative assessment of the three epidemics. Acta Neurol Scand 76: 317-339.

165. Miller DH, Hammond SR, McLeod JG, Purdie G, Skegg DC (1990) Multiple sclerosis in Australia and New Zealand: are the determinants genetic or environmental? J Neurol Neurosurg Psychiatry 53: 903-905.

166. Simpson S Jr, Blizzard L, Otahal P, Van der Mei I, Taylor B (2011) Latitude is significantly associated with the prevalence of multiple sclerosis: a metaanalysis. J Neurol Neurosurg Psychiatry 82: 1132-1141.

167.Kurtzke JF (1993) Epidemiologic evidence for multiple sclerosis as an infection. Clin Microbiol Rev 6: 382-427.

168. Cuzner ML (1980) Annotation. Recent biochemical and immunological observations in multiple sclerosis. Neuropathol Appl Neurobiol 6: 405-414.

169. Adams CW, Poston RN, Buk SJ, Sidhu YS, Vipond H (1985) Inflammatory vasculitis in multiple sclerosis. J Neurol Sci 69: 269-283.

170.Westall FC (2006) Molecular mimicry revisited: gut bacteria and multiple sclerosis. J Clin Microbiol 44: 2099-2104.

171.Steiner I, Nisipianu P, Wirguin I (2001) Infection and the etiology and pathogenesis of multiple sclerosis. Curr Neurol Neurosci Rep 1: 271-276.

172. Giovannoni G, Cutter GR, Lunemann J, Martin R, Münz C, et al. (2006) Infectious causes of multiple sclerosis. Lancet Neurol 5: 887-894.

173. Mielcarz DW, Kasper LH (2015) The gut microbiome in multiple sclerosis. Curr Treat Options Neurol 17: 344.

174. Petra Al, Panagiotidou S, Hatziagelaki E, Stewart JM, Conti P, et al. (2015) Gut-Microbiota-Brain axis and its effect on neuropsychiatric disorders with suspected immune dysregulation. Clin Ther 37: 984-995.

175. Bhargava P, Mowry EM (2014) Gut microbiome and multiple sclerosis. Curr Neurol Neurosci Rep 14: 492.

176. Le Gac P (1960) The treatment of multiple sclerosis of rickettsial or neorickettsial origin. J Med Bord 137: 577-589.

177. Sriram S, Mitchell W, Stratton C (1998) Multiple sclerosis associated with Chlamydia pneumoniae infection of the CNS. Neurology 50: 571-572.

178. Parratt J, Tavendale R, O'Riordan J, Parratt D, Swingler R (2008) Chlamydia pneumoniae-specific serum immune complexes in patients with multiple sclerosis. Mult Scler 14: 292-299.

179. Grimaldi LME, Pincherle A, Martinelli-Boneschi F, Filippi M, Patti F, et al. (2003) An MRI study of Chlamydia pneumoniae infection in Italian multiple sclerosis patients. Mult Scler 9: 467-471.

180.Gutiérrez J, Koppel B, Kleiman A, Akfirat G (2008) Multiple sclerosis and Epstein-Barr virus: a growing association. Rev Med Inst Mex Seguro Soc 46: 639-642.
181. Abdelrahman HS, Selim HS, Hashish MH, Sultan LI (2014) Epstein-Barr virus in multiple sclerosis. J Egypt Public Health Assoc 89: 90-95.

182. Leibovitch EC, Jacobson S2 (2014) Evidence linking HHV-6 with multiple sclerosis: an update. Curr Opin Virol 9: 127-133.

183. Broccolo F, Fusetti L, Ceccherini-Nelli L (2013) Possible role of human herpesvirus 6 as a trigger of autoimmune disease. ScientificWorldJournal 2013: 867389.

184. Ferrò MT, Franciotta D, Prelle A, Bestetti A, Cinque $P$ (2012) Active intratheca herpes simplex virus type 1 (HSV-1) and human herpesvirus-6 (HHV-6) infection at onset of multiple sclerosis. J Neurovirol 18: 437-440.

185. Stratton CW, Wheldon DB (2006) Multiple sclerosis: an infectious syndrome involving Chlamydophila pneumoniae. Trends Microbiol 14: 474-479.

186. Thibault PK (2012) Multiple sclerosis: a chronic infective cerebrospinal venulitis? Phlebology 27: 207-218.

187. Ransohoff RM, Hafler DA, Lucchinetti CF (2015) Multiple sclerosis-a quie revolution. Nat Rev Neurol 11: 134-142.

188. Christiansen CF1 (2012) Risk of vascular disease in patients with multiple sclerosis: a review. Neurol Res 34: 746-753.

189. Wei L, MacDonald TM, Walker BR (2004) Taking glucocorticoids by prescription is associated with subsequent cardiovascular disease. Ann Intern Med 141: 764-770.

190. Christiansen CF, Christensen S, Mehnert F, Cummings SR, Chapurlat RD, et al. (2009) Glucocorticoid use and risk of atrial fibrillation or flutter: a populationbased, case-control study. Arch Intern Med 169: 1677-1683.

191.Sonnenblick M, Rosin A (1991) Cardiotoxicity of interferon. A review of 44 cases. Chest 99: 557-561.

192. Le Page E, Leray E, Edan G. (2011) Long-term safety profile of mitoxantrone in a French cohort of 802 multiple sclerosis patients: a 5 -year prospective study. Mult Scler 17: 867-875.

193. Kappos L, Radue EW, O'Connor P, Polman C, Hohlfeld R, et al. (2010) A placebo-controlled trial of oral fingolimod in relapsing multiple sclerosis. $\mathrm{N}$ Engl J Med 362: 387-401.

194. Pelletier D, Hafler DA (2012) Fingolimod for multiple sclerosis. N Engl J Med 366: 339-347

195. Schwarz A, Korporal M, Hosch W, Max R, Wildemann B (2010) Critical vasospasm during fingolimod (FTY720) treatment in a patient with multiple sclerosis. Neurology 74: 2022-2024.

196. Sheremata WA, Taylor JR, Elgart GW (1995) Severe necrotizing cutaneous lesions complicating treatment with interferon beta-1b. N Engl J Med 332 1584.

197. Elgart GW, Sheremata W, Ahn YS (1997) Cutaneous reactions to recombinant human interferon beta- $1 \mathrm{~b}$ : the clinical and histologic spectrum. J Am Acad Dermatol 37: 553-558.

198. Samuel L, Lowenstein EJ (2006) Recurrent injection site reactions from interferon beta 1-b. J Drugs Dermatol 5: 366-367. 